\title{
Effect of abiotic factors on bacoside A content, acetylcholinesterase inhibitory and antioxidant activities of Bacopa monnieri (L.) Wettst
}

\author{
Varinder Singh ${ }^{1^{*}}$, Naman Jain ${ }^{2}$, Richa Shri ${ }^{*}$ \\ ${ }^{1}$ Chitkara College of Pharmacy, Chitkara University, Punjab, India. \\ ${ }^{2}$ Department of Pharmaceutical Sciences and Drug Research, Punjabi University, Patiala, Punjab, India.
}

\section{ARTICLE INFO \\ Received on: 06/12/2019 \\ Accepted on: 03/07/2020 \\ Available online: 25/02/2021}

\section{Key words:}

Abiotic stresses, acetylcholinesterase inhibition, antioxidant activity, Bacopa monnieri, bacoside A.

\begin{abstract}
Growth of plants and production of phytoconstituents are influenced by abiotic stresses. Understanding these abiotic factors and their subsequent modification during cultivation/growth of medicinal plants may help in increasing the production of valuable secondary metabolites. The present study examined the effect of various abiotic factors and seasons on the growth of Bacopa monnieri, production of the marker compound bacoside A, and antioxidant and acetylcholinestrase inhibitory activities of the plant extract. The plant was cultivated in two different soils, viz A (clay loam soil) and B (sandy loam soil). Different abiotic stresses, i.e., water stress, fertilization, light, and salinity, were applied in two seasons (season 1: July to November and season 2: February to May). Bacoside A content in methanol extracts of the dried aerial parts of plants grown under different stresses was determined using a validated thin layer chromatography (TLC) densitometric method. In vitro 2,2-diphenyl-1-picrylhydrazyl (DPPH) assay and Ellman's method were employed to evaluate the antioxidant and acetylcholinestrase inhibitory activities of different extracts, respectively. Best plant growth was observed in soil A in season 1. Plants grown in season 2 had a significantly higher bacoside A content, better antioxidant, and acetylcholinestrase inhibitory activities than the plants grown in season 1. Among various stresses applied in season 2, plants grown in soil B, especially water stress-effected plants, had the highest bacoside A content, antioxidant, and acetylcholinestrase inhibitory activities. The plant should be cultivated from February to May in sandy loam soil with water stress for enhanced production of the marker compound and significant bioactivities.
\end{abstract}

\section{INTRODUCTION}

Growth of plants and production of phytoconstituents are greatly influenced by biotic and abiotic factors. Plants respond to abiotic factors, i.e., altered or adverse environmental influences, by modifying their morphology, physiology, and biochemistry (Rejeb et al., 2014; Shanker and Venkateswarlu, 2011). One approach of adaptation to stress by plants includes change in nature and quantity of primary and secondary metabolites (Ramakrishna and Ravishankar, 2011). Understanding the influence of modifiable external factors on the production of secondary metabolites can help in determining ideal conditions for growth so that the content

Abstract of this article was presented at CUDC consortium and Summer School Conference at Chitkara University, India.

*Corresponding Author

Varinder Singh, Chitkara College of Pharmacy, Chitkara University, Punjab, India.E-mail: varinder.9096@chitkara.edu.in

Richa Shri, Department of Pharmaceutical Sciences and Drug Research, PunjabiUniversity, Patiala,India.E-mail: rshri587@hotmail.com of the desired plant metabolites may be optimized (Ghershenzon, 1984). This can be especially useful for the cultivation of plants that are valued in the traditional as well as modern systems of medicine. One such plant is Bacopa monnieri (L.) Wettst. (Synonym Herpestis monnieri; family Scrophulariaceae). Commonly known as Brahmi, it is an annual/biennial creeping herb found throughout the Indian subcontinent in wet and marshy places (Khare, 2007; Russo and Borrelli, 2005). It is a fast growing plant and used as a "medhya-rasayana" in Ayurveda because of its cognition-enhancing properties (Singh, 2013). Scientific evidence also shows that this plant is extremely valuable for enhancing memory and intellect (Aguiar and Borowski, 2013). The cognitionenhancing effect is mainly attributed to the Bacoside $\mathrm{A}$ - a mixture of triterpenoid saponins present in the plant (Bansal et al., 2015; Singh et al., 1988).

Although cultivation practices for this plant are well documented, these reports do not describe the effect of different abiotic factors on the active constituents or the activity of this common but highly revered plant (Board, 2003; Farooqi and 
Sreeramu, 2014). Hence, in the present study, the effect of abiotic stresses on the production of marker compound (bacoside A) and on the plant's antioxidant and acetylcholinesterase (AChE) inhibitory activities were evaluated with a view to understand which soil to use, which season to prefer, and what environmental conditions to use during cultivation to enhance the production of Bacoside $\mathrm{A}$ in the cultivated plants, and hence augment its cognition-enhancing activity.

\section{MATERIALS AND METHODS}

Plant material

The fresh plantlets of B. monnieri L. (Scrophulariaceae) were procured from a cultivated source at the National Institute of Pharmaceutical education and Research, Mohali, Punjab, India, in September 2014. The plant was identified and authenticated by Dr. V.K Singhal, Professor, Department of Botany, Punjabi University, Patiala, India.

Chemical and solvents

AChE, acetylthiocholine iodide (ATI), 5,5-dithio-bis(2-nitrobenzoic acid) (DTNB), various chemicals, solvents, and reagents used in the preparation of extracts and their standardization were of analytical (AR) grade.

Field experiment

Figure 1 shows the plan of work of the present investigation.

The field experiment was conducted at the Medicinal Plant Garden, Department of Pharmaceutical Sciences and Drug Research, Punjabi University, Patiala, Punjab, India, in two seasons, namely:
- Season 1: July to November 2014 (collection in the first week of December)

- Season 2: February to May 2015 (collection in the first week of June).

\section{Preparation of experimental plots}

Two types of soils were selected for this investigation, viz clay loam (soil A) and sandy loam (soil B). The field work was conducted in five plots and five pots, each of size $1 \times 1 \mathrm{~m}$, filled with soil A and soil B, respectively. Farmyard manure $\left(3 \mathrm{~kg} / \mathrm{m}^{2}\right)$ was added in all plots and pots.

\section{Propagation}

The plantlets with $5 \mathrm{~cm}$ of length were directly planted in plots and pots at a distance of $10 \mathrm{~cm}$ in a row and each row was $10 \mathrm{~cm}$ apart. The plantlets were immediately irrigated after propagation.

Plot 1 and pot 1 were taken as the control in which no abiotic stress was applied. For 1 month, all plants were allowed to grow under normal conditions and irrigation was done on alternative days.

Application of abiotic stresses

After 1 month, the following different abiotic stresses were applied:

(A) Salt Stress: Salt stress was applied by pouring 5\% $w / v$ solution of sodium chloride at monthly interval in plot 2 and pot 2 .

(B) Water stress: Plot 3 and pot 3 were irrigated every 5 days instead of alternative days.

\section{Bacopa monniera plants were grown in 2 seasons}

Season 1: July to November 2014

Season 2: February to May 2015

Plants in each season were grown in two soil types:

Soil A:

Clay loam soil +FYM
Soil B:

Sandy loam +FYM

In each soil type for both seasons the plants were subjected to the following abiotic stresses:

Control

Drought

Fertilization

Shade

Salt stress

-At the end of each season, plants were collected, dried and weighed.

-Their methanol extracts were prepared. The prepared extracts were subjected to:

$>$ Phytochemical screening

$>$ Determination of marker content (i.e. Bacoside A content) using an

HPTLC method

Evaluation of antioxidant and anticholinesterase activities

Figure 1. Summary of the plan of work. 
(C) Fertilization: The following fertilizers were applied together in plot 4 and pot 4 in the specified quantity at monthly intervals:

- Urea: $5 \mathrm{~g} / \mathrm{m}^{2}$

- Phosphorus: $8 \mathrm{~g} / \mathrm{m}^{2}$

- Potash: $4 \mathrm{~g} / \mathrm{m}^{2}$

- Zinc sulfate: $4 \mathrm{~g} / \mathrm{m}^{2}$

(D) Light: Plot 5 and pot 5 were kept under full shade conditions.

\section{Collection of plants}

The first collection of aerial parts of plants was done in the first week of December. The next collection was done in the first week of June between 10 and $11 \mathrm{am}$.

\section{Preparation of extracts}

The collected aerial parts were dried in the shade, coarsely powdered, and macerated with methanol at $36.6^{\circ} \pm 1^{\circ} \mathrm{C}$ at $80 \mathrm{rpm}$ in a shaking incubator for 48 hours. After filtration, the marc was again macerated by adding fresh methanol for 24 hours at $36.6^{\circ} \pm 1^{\circ} \mathrm{C}$ at $80 \mathrm{rpm}$ in a shaking incubator and filtered. The obtained filtrates were combined and concentrated on a water bath. The extracts were dried and weighed, and the percentage yield was calculated on dry weight basis.

\section{Phytochemical screening}

The extracts were tested for the presence or absence of various classes of phytoconstituents (Farnsworth, 1966).

\section{TLC densitometric method for estimation of bacoside A}

The following chromatographic conditions were used to quantify bacoside A:

- Standard: $1 \mathrm{mg} / \mathrm{ml}$ of bacoside A

- Sample: $5 \mathrm{mg} / \mathrm{ml}$ of methanol extracts of $B$. monnieri plants grown under various conditions

- Stationary phase: Pre-coated silica gel $\mathrm{GF}_{254}$ plates (E Merck, Mumbai, India, $0.2 \mathrm{~mm}$; aluminum base)

- Solvent system: toluene: ethyl acetate: methanol: formic acid (3: 3.5: 2.5: $1 \mathrm{v} / v / v / v)$

- Spraying reagent: $p$-anisaldehyde sulfuric reagent

- Plate size: $10 \times 10 \mathrm{~cm}$

- Band width: $6 \mathrm{~mm}$

- Sample volume: $10 \mu 1$

- Temperature: Ambient room temperature

- Migration distance: $8 \mathrm{~cm}$

- Detection wavelength: $530 \mathrm{~nm}$

- Instrument: CAMAG HPTLC system equipped with a sample applicator Linomat 5 , Twin trough plate development chamber, TLC Scanner IV, and WinCATS software 1.4.8 (CAMAG Scientific Inc., Wilmington, NC)

\section{Preparation of standard plot}

The stock solution of bacoside A $(1 \mathrm{mg} / \mathrm{ml})$ was prepared in methanol and diluted to get different concentrations $(30,50,70$, $90,110,130,140,170,180$, and $190 \mu \mathrm{g} / \mathrm{ml})$. A volume of $10 \mu \mathrm{l}$ from each dilution was applied, in triplicate, on a pre-coated TLC plate using Linomat 5 sample applicator. The plate was developed to a distance of $8 \mathrm{~cm}$ in a twin trough chamber pre-saturated (10 minutes) with solvent system. The plate was then removed and dried in a hot air oven at $100^{\circ} \mathrm{C}$ for 1 minute. After drying, the plate was derivatized using p-anisaldeyde sulfuric acid reagent and dried at $100^{\circ} \mathrm{C}$ to visualize the bands of bacoside $\mathrm{A}$. The developed plate was scanned at $530 \mathrm{~nm}$ using TLC Scanner IV and area under the curve of the peak corresponding to bacoside $\mathrm{A}$ was noted.

\section{TLC finger print profiles}

A volume of $10 \mu \mathrm{l}$ each of bacoside A and methanol extracts obtained from $B$. monnieri were applied separately, in triplicate, on a pre-coated TLC plate and the plate was developed, derivatized, and scanned following the same procedure used for the preparation of standard plot. The chromatographic profiles of bacoside A and different extracts of B. monnieri were compared. The amount of bacoside $A$ in various extracts was calculated from its linear calibration plot and the percentage content was calculated with respect to the dried plant extract.

The method was validated in terms of linearity, precision, repeatability, inter and intra-day variations, limit of detection (LOD), limit of quantification (LOQ), specificity, and recovery following International Council for Harmonisation (ICH) guidelines (Randhawa et al., 2015).

\section{In vitro evaluation of biological activities of the extracts}

In vitro antioxidant activity

The antioxidant activity of various plant extracts were tested by the DPPH (2,2-diphenyl-1-picrylhydrazyl) assay (Blois, 1958; Singh et al., 2017).

DPPH radical scavenging activity was expressed as the $\%$ inhibition calculated using the following equation:

$\%$ Inhibition $=\{($ Absorbance of control - Absorbance of test sample)/Absorbance of control $\} \times 100$

The $\mathrm{IC}_{50}(\mu \mathrm{g} / \mathrm{ml})$ value of different extracts were calculated by using linear regression analysis.

In vitro $A C h E$ inhibitory activity

The inhibitory effect of the test extract on AChE activity was evaluated by the spectrophotometric method of Ellman et al. (1961). Tacrine (10-80 $\mu \mathrm{g} / \mathrm{ml})$ was used as standard AChE inhibitor. The control, standard, and test samples contained the following:

- $\quad$ Control $=$ Phosphate buffer $(0.1 \mathrm{M}, 8 \mathrm{pH}, 2.6 \mathrm{ml})+$ DTNB $(0.01 \mathrm{M}, 0.1 \mathrm{ml})+$ distilled water $(0.1 \mathrm{ml})+$ $\operatorname{AChE}\left(0.1 \mathrm{U} \mathrm{ml}^{-1}, 0.1 \mathrm{ml}\right)+\mathrm{ATI}(0.075 \mathrm{M}, 0.1 \mathrm{ml})$.

- $\quad$ Standard $=$ Phosphate buffer $(0.1 \mathrm{M}, 8 \mathrm{pH}, 2.6$ $\mathrm{ml})+\operatorname{DTNB}(0.01 \mathrm{M}, 0.1 \mathrm{ml})+$ tacrine $(0.1 \mathrm{ml})+$ $\operatorname{AChE}\left(0.1 \mathrm{U} \mathrm{ml}^{-1}, 0.1 \mathrm{ml}\right)+\operatorname{ATI}(0.075 \mathrm{M}, 0.1 \mathrm{ml})$.

- $\quad$ Test $=$ Phosphate buffer $(0.1 \mathrm{M}, 8 \mathrm{pH}, 2.6 \mathrm{ml})+$ DTNB $(0.01 \mathrm{M}, 0.1 \mathrm{ml})+\operatorname{extract}(0.1 \mathrm{ml})+\mathrm{AChE}$ $\left(0.1 \mathrm{U} \mathrm{ml}^{-1}, 0.1 \mathrm{ml}\right)+$ ATI $(0.075 \mathrm{M}, 0.1 \mathrm{ml})$.

All the readings were taken in triplicate. The percentage inhibition was calculated in comparison to control (extract absent). The percentage inhibition was calculated using the following equation:

$\%$ Inhibition $=1-($ absorbance of test sample $/$ absorbance of control) $\times 100$ 


\section{Statistical analysis}

Data were presented as mean \pm S.D. $t$-test was used as a statistical test for comparing bacoside A content, DPPH, and AChE inhibitory activity of plants grown under different abiotic stresses in season 1 with the respective plants grown in season 2 .

\section{RESULTS AND DISCUSSION}

Biotic and abiotic environmental conditions are dynamic and constantly changing. Plants adjust to any change in the environment by modifying their morphology, physiology, and phytochemistry (i.e., changes in nature as well as amount of primary and secondary metabolites). In the present study, the effect of various abiotic factors on growth, marker content, and activities of $B$. monnieri was examined.

\section{Effect of abiotic factors on plant growth}

The present investigation showed variations in plant growth with change in seasons. Growth was found to be higher in season 2, i.e., February to May. Our results concur with Phrompittayarat et al. (2011) who had reported the highest growth of B. monnieri in summer (March to June). Mathur et al. (2000) also reported that the lowest growth of brahmi was found in winter (September to December), which is consistent with the present results.

Abiotic stresses, like increase in salinity (Ahire et al., 2013) and water stress (Zobayed et al., 2007), are reported to effect plant growth adversely. In the present study, it was observed that the growth was lowest in plants subjected to water stress in both soils. Bacopa monnieri is reported to have a healthy growth near water bodies (Chopra et al., 1956), thus the reduction in the amount of water during growth can affect the plant yield.

The present investigation showed the variation of growth in two different soils. Plants grown in soil B (sandy loam) showed better growth with respect to plants grown in soil A (clay loam). The results are in harmony with a study suggesting high plant growth in sandy loam soil (Baruah et al., 2014). Negligible growth was observed under the following conditions:

\begin{tabular}{ccl}
\hline Season & Soil & Stress condition \\
\hline 1 & A & Water stress; shade \\
& B & Fertilization; shade \\
2 & A & Shade \\
& B & Shade \\
\hline
\end{tabular}

\section{Effect of abiotic stresses on B. monnieri extract yield}

At the end of each season, the plants grown under various stresses were collected and their methanol extracts were prepared. Table 1 summarizes the yield ( $\% \mathrm{w} / \mathrm{w}$, dry weight basis) of methanol extract obtained from plants grown under different conditions.

Phytochemical screening of all the prepared extracts showed the presence of alkaloids, carbohydrate, flavonoids, saponins, steroids, and terpenoids.

\section{Estimation of bacoside a in extracts of different stress-effected plants of B. monnieri using TLC densitometric method}

Plants produce secondary metabolites to cope with any environmental alterations; this is a stress tolerance mechanism of plants (Bennet and Wallsgrove, 1994; Ramakrishna and
Table 1. Yield of methanol extracts of B. monnieri plants grown under different abiotic stresses.

\begin{tabular}{|c|c|c|c|}
\hline Soil type & Abiotic stress & $\begin{array}{c}\text { Yield ( } \% w / w, \text { dry weight } \\
\text { basis) Season } 1\end{array}$ & $\begin{array}{c}\text { Yield ( } \% w / w, \text { dry weight } \\
\text { basis) Season } 2\end{array}$ \\
\hline \multirow[t]{5}{*}{ A } & Control & 25 & 27 \\
\hline & Water stress & - & 30 \\
\hline & Fertilizer & 31.7 & 33 \\
\hline & Shade & - & - \\
\hline & Salt stress & 30 & 31 \\
\hline \multirow[t]{5}{*}{ B } & Control & 27 & 30 \\
\hline & Water stress & 22 & 24 \\
\hline & Fertilizer & - & 25 \\
\hline & Shade & - & - \\
\hline & Salt stress & 25 & 25 \\
\hline
\end{tabular}

Negligible plant growth hence no extract could be prepared.

Table 2. TLC densitometric method validation parameters for analysis of bacoside $\mathrm{A}$ in $B$. monnieri leaves.

\begin{tabular}{lc}
\hline Parameter & Values \\
\hline Instrumental precision $(\% \mathrm{CV}, n=7)$ & 0.78 \\
Repeatability $(\% \mathrm{CV}, n=5)$ & 0.98 \\
Coefficient of correlation & 0.998 \\
Linearity range (ng) & $300-1900$ \\
Intra-day precision $(\% \mathrm{CV}, n=9)$ & 1.3 \\
Inter-day precision $(\% \mathrm{CV}, n=9)$ & 1.7 \\
LOD (ng) & 215 \\
LOQ (ng) & 255 \\
Accuracy (average $\%$ recovery) & 98.56 \\
Specificity & Specific \\
\hline
\end{tabular}

Ravishankar, 2011). Bacoside A is a secondary metabolite mainly responsible for the cognition improvement activity of $B$. monnieri (Singh et al., 1988; Sukumaran et al., 2019). A TLC densitometric method was used for the determination of Bacoside A content in plants grown under different conditions. TLC densitometric methods have been described in the literature for the estimation of bacoside A content (Ahmed et al., 2015; Pawar and Jadhav, 2015). But, in our laboratory conditions, the appropriate separation of bacoside A was achieved by slightly modifying the method described by Pawar and Jadhav (2015). Therefore, the modified method was validated as per ICH guidelines. The results of method validation parameters are shown in Table 2.

The method showed a good correlation coefficient of 0.998 when peak areas of bacoside A were plotted against its concentrations, exhibiting good linearity (Fig. 2). The percentage coefficient of variance $(\% \mathrm{CV})$ in validation parameters of the developed method was found within the acceptable limits. The identity of bacoside A bands in extracts was confirmed by comparing Rf values and thin layer chromatogram with those of the standard. The proposed method was found to be accurate as all spiked contents were extracted and quantified with average 


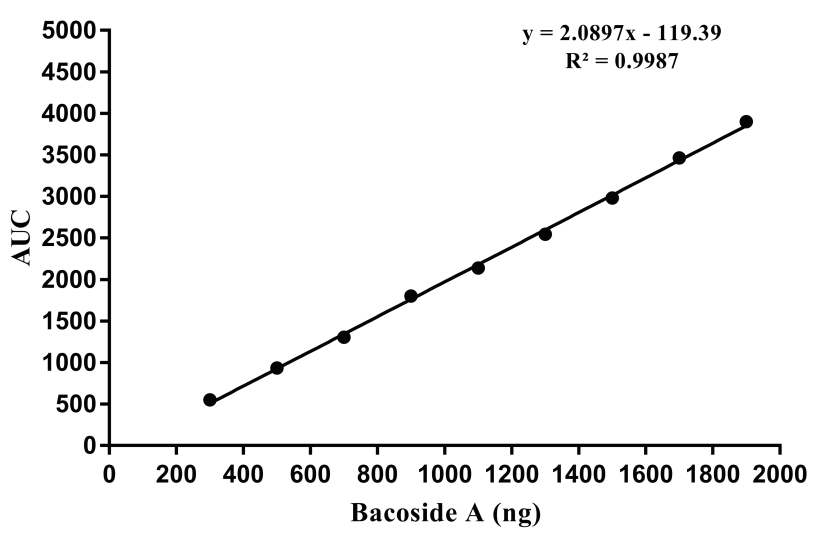

Figure 2. Standard plot between the mean peak area and amount of bacoside A.

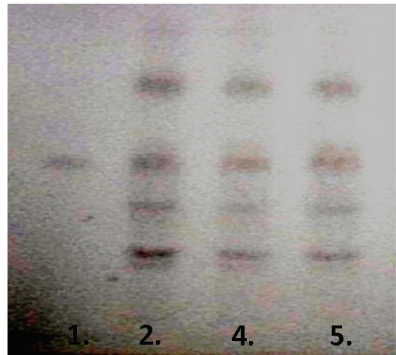

Soil A season 1

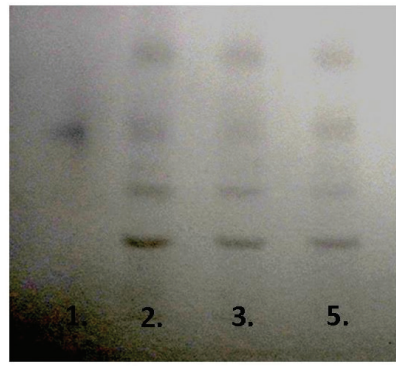

Soil B season 1

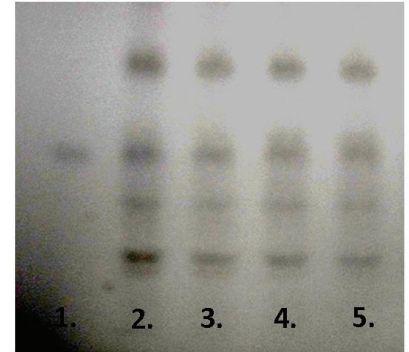

Soil A season 2

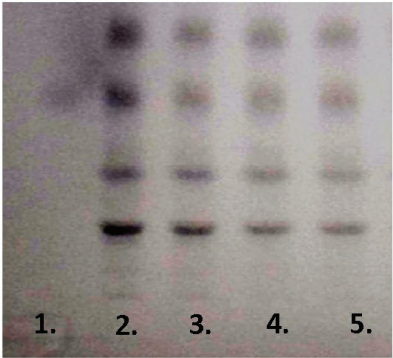

Soil B season 2
Figure 3. Comparative TLC fingerprint profile of bacoside A (1) and extracts of control (2), water stress (3), fertilizer (4), and salt stress (5) effected plants observed after derivatization with $\mathrm{p}$-anisaldehyde sulfuric acid reagent. recovery of 98.56 for bacoside A (Table 2). These observations suggest that the developed method for the estimation of bacoside A is precise, accurate, reproducible, and specific.

TLC fingerprint profile of various prepared methanol extracts showed the presence of bacoside A in all extracts (Fig. 3). The percent content of bacoside A in plants grown under various stresses in different seasons is presented in Table 3. Earlier studies have reported variations in the content of total bacosides and bacoside A in different seasons (Mathur et al., 2002; Phrompittayarat et al., 2011; Sharma et al., 2013). In the present study, methanol extract of all plants grown under different stresses in season 2 had a significantly $(p<0.05)$ higher bacoside A content as compared to plants grown under respective stresses in season 1 (Table 3).

The results also show that the water stress-effected plant in season 2 and soil B had the highest quantity of bacoside A $(0.1186 \% \mathrm{w} / \mathrm{w})$ as compared to all control and all other stresseffected plants. It is reported that abiotic stresses, especially water stress, have a strong effect on the secondary metabolites production in plants (Albergaria et al., 2020; Hodaei et al., 2018; Kleinwächter and Selmar, 2015). The literature showed an increase in epicatechin in Camelia sinesis (Hernández et al., 2006), ajmalicine in Catharanthus roseus (Jaleel et al., 2008), phenolic content in Trachyspermum ammi L. (Azhar et al., 2011), and thymol, carvacrol, and trans-caryophyllene in essential oil of Thymus eriocalyx (Amiri et al., 2018) under water stress. The increase in secondary metabolite content in plants was related to its protective mechanism against water stress-induced oxidative stress (Kleinwächter and Selmar, 2015). Probably, the increase in bacoside A content in the present investigation was the plant's protective mechanism against stress. Hence, it is beneficial to irrigate the plant $B$. monnieri with 4 days interval than on alternative days since this triggers the plant to produce higher quantities of bacoside $\mathrm{A}$.

\section{Effect of abiotic factors on the antioxidant activity of B. monnieri plants}

In the present investigation, the antioxidant potential was determined by DPPH assay and results were expressed in terms of $\mathrm{IC}_{50}$ values (Table 4). The $\mathrm{IC}_{50}$ value refers to the minimum concentration required for $50 \%$ inhibition of free radicals. Hence, the smaller the $\mathrm{IC}_{50}$ value, the more the antioxidant potential.

Table 3. Percentage content of bacoside A in B. monnieri plant extracts

\begin{tabular}{|c|c|c|c|}
\hline Soil type & Abiotic stress & $\begin{array}{c}\text { Percentage content }(\% w / w) \text { of bacoside } A \text { in } \\
\text { extracts }\left(\operatorname{Mean}^{\mathrm{n}} \pm \text { S.D)Season } 1\right.\end{array}$ & $\begin{array}{c}\text { Percentage content }(\% w / w) \text { of bacoside } A \text { in } \\
\text { extracts }\left(M_{\text {Mean }}{ }^{\mathrm{n}} \pm \text { S.D)Season } 2\right.\end{array}$ \\
\hline \multirow[t]{4}{*}{ A } & Control & $0.0252 \pm 0.0045$ & $0.0823 \pm 0.0043^{*}$ \\
\hline & Water stress & - & $0.1011 \pm 0.0055^{*}$ \\
\hline & Fertilizer & $0.0407 \pm 0.0056$ & $0.0643 \pm 0.0012 *$ \\
\hline & Salt stress & $0.0332 \pm 0.0032$ & $0.0803 \pm 0.0034 *$ \\
\hline \multirow[t]{4}{*}{ B } & Control & $0.0520 \pm 0.0012$ & $0.0997 \pm 0.0018^{*}$ \\
\hline & Water stress & $0.0822 \pm 0.0043$ & $0.1186 \pm 0.0011^{*}$ \\
\hline & Fertilizer & - & $0.0912 \pm 0.0022 *$ \\
\hline & Salt stress & $0.07 \pm 0.0033$ & $0.0810 \pm 0.0044 *$ \\
\hline
\end{tabular}

The data are expressed as mean $\pm \mathrm{SD}$ and analyzed by $t$-test of independent samples. $*^{*} p 0.05$ versus respective stress in season 1 . 
Table 4. The $\mathrm{IC}_{50}$ values of the plants grown under different conditions in the DPPH assay.

\begin{tabular}{clcc}
\hline Soil & Sample & $\mathbf{I C}_{\mathbf{5 0}}$ value $(\boldsymbol{\mu g} / \mathbf{m l})\left(\mathbf{M e a n}^{\mathbf{n}} \pm \mathbf{S . D}\right)$ Season 1 & $\mathbf{I C}_{\mathbf{5 0}}$ value $(\boldsymbol{\mu g} / \mathbf{m l})\left(\mathbf{M e a n} \mathbf{n}^{\mathbf{n}} \mathbf{S . D}\right)$ Season $\mathbf{2}$ \\
\hline \multirow{3}{*}{ A } & Ascorbic acid (Standard) & $5.2 \pm 0.6$ & $5.2 \pm 0.6$ \\
& Control & $47.9 \pm 0.6$ & $38.9 \pm 0.5^{*}$ \\
& Water stress & - & $41.9 \pm 0.4^{*}$ \\
& Fertilizer & $52.9 \pm 0.2$ & $46.4 \pm 0.3^{*}$ \\
& Salinity & $39.3 \pm 1.3$ & $26.4 \pm 0.4^{*}$ \\
B & Control & $39.7 \pm 1.4$ & $27.4 \pm 0.3^{*}$ \\
& Water stress & $29.5 \pm 0.7$ & $26.2 \pm 0.4^{*}$ \\
& Fertilizer & - & $26.7 \pm 0.3^{*}$ \\
& Salinity & $29.7 \pm 0.7$ & $25.1 \pm 0.5^{*}$ \\
\hline
\end{tabular}

The data are expressed as mean $\pm \mathrm{SD}$ and analyzed by $t$-test of independent samples.

$*=p<0.05$ versus respective stress in season 1 .

Table 5. The $\mathrm{IC}_{50}$ values of the AChE inhibitory assay of the plants for both the seasons.

\begin{tabular}{clcc}
\hline Soil & Sample & $\mathbf{I C}_{\mathbf{5 0}}$ value $(\mathbf{m g} / \mathbf{m l})\left(\mathbf{M e a n}^{\mathbf{n}} \pm \mathbf{S . D}\right)$ Season 1 & $\mathbf{I C}_{\mathbf{5 0}}$ value $(\mathbf{m g} / \mathbf{m l})\left(\mathbf{M e a n} \mathbf{n}^{\mathbf{n}} \mathbf{\text { S.D }}\right)$ Season 2 \\
\hline \multirow{3}{*}{ A } & Tacrine (Standard) & $0.019 \pm 0.003$ & $0.019 \pm 0.003$ \\
& Control plant & $6.9 \pm 0.1$ & $4.5 \pm 0.4^{*}$ \\
& Water stress plant & - & $3.3 \pm 0.5^{*}$ \\
& Fertilized plant & $5.7 \pm 0.3$ & $5.0 \pm 0.3^{*}$ \\
& Salinity plant & $5.8 \pm 0.5$ & $4.1 \pm 0.2^{*}$ \\
B & Control plant & $5.4 \pm 0.4$ & $3.9 \pm 0.2^{*}$ \\
& Water stress plant & $4.1 \pm 0.3$ & $3.4 \pm 0.3^{*}$ \\
& Fertilized plant & - & $4.1 \pm 0.3^{*}$ \\
& Salinity plant & $4.8 \pm 0.2$ & $4.3 \pm 0.2^{*}$ \\
\hline
\end{tabular}

The data are expressed as mean $\pm \mathrm{SD}$ and analyzed by $t$-test of independent samples.

$* p<0.05$ versus respective stress in season 1 .

Seasonal variations are reported to affect the bioactivities of plants. For example, Hussain et al. (2008) reported that the Ocimum basilicum essential oils obtained from winter and spring crops showed greater free radical scavenging activity than those collected during autumn and summer. In the present study, plants grown in season 2 showed significantly $(p<0.05)$ higher antioxidant potential than the respective season 1 plants (Table 4). Literature shows that bacoside A present in B. monnieri contributes to its antioxidant activity (Bhattacharya et al., 2000; Jauhari et al., 2019; Simpson et al., 2015). Thus, as observed in the current study, higher antioxidant activity of plants grown in season 2 may be attributed to higher bacoside A content of the plants. Moreover, plants grown in soil B showed marked antioxidant activity.

It is reported that water stress is one of the most important environmental stresses that can alter growth and bioactivity of plants (Ghanbarzadeh et al., 2019; Kleinwächter and Selmar, 2015). Studies have pointed out that drought-tolerant species increased their antioxidant enzyme activities in response to drought treatment, whereas drought-sensitive species failed to do so (Masoumi et al., 2011). Zhu et al. (2009) found that the water stress conditions could intensify DPPH scavenging activity of Bupleurum spp. It is also documented that salt stress resulted in increased bacoside A amount in in-vitro regenerated shoots of B. monnieri (Ahire et al., 2013). In the present study, among the various abiotic stresses given to the plants grown under season 2 and soil B, water stress and salinity-affected plants were found to have significantly ( $p<$ 0.05 ) higher antioxidant activity than the control plants. This could be due to higher bacoside A content, since bacoside A is responsible for antioxidant activity of B. monnieri (Ahire et al., 2013).

Effect of abiotic factors on the $\mathrm{AChE}$ inhibition by B. monnieri

According to the cholinergic hypothesis of dementia, cholinergic neurotransmitters, especially acetylcholine, play a crucial role in the regulation of cognitive functions. Diminished cholinergic neurotransmission due to breakdown of acetylcholine by $\mathrm{AChE}$ in the brain results in cognitive impairment (Pinto et al., 2011). Hence, the enhancement of central cholinergic activity with use of AChE inhibitors is presently the mainstay of the pharmacotherapy for cognitive enhancement in dementia of Alzheimer's type (Singh et al., 2013). Since B. monnieri has been used traditionally to treat cognitive disorders and scientific investigations elucidates that $\mathrm{AChE}$ inhibition is one of the main mechanisms by which it improves memory impairment; therefore, it was necessary to investigate the impact of various abiotic stresses on the AChE inhibitory activity of plant (Aguiar and Borowski, 2013; Mathew and Subramanian, 2014).

The results of the present investigation revealed that plants grown under different stresses in season 2 have a significantly higher AChE inhibitory activity than respective plants grown in season 1 (Table 5). Bacoside A has been documented as potential AChE inhibitor and memory enhancer (Ramasamy et al., 2015; Singh et al., 1988). Therefore, higher AChE inhibitory activity observed in the present investigation, in season 2 plants, might be due to higher bacoside A content. 
Also, plants grown in soil B have better AChE inhibitory activity than the plants grown in soil A. The water stress-effected plants in both soil types have the highest inhibitory activity, which is probably due to higher bacoside A content.

\section{CONCLUSION}

Bacopa monnieri grows well as a perennial plant with annual cycles of active growth, especially near water bodies or with daily irrigation. However, from our study, it is concluded that for enhanced production of bacoside A and increased activity, this medicinally important plant should be given water stress (irrigation after 4 days) and should be cultivated in sandy loam soil during the period from February to May and harvested in June.

\section{ACKNOWLEDGMENTS}

The authors are very thankful to the Department of Pharmaceutical Sciences and Drug Research, Punjabi University, Patiala, Punjab, India, for providing all the necessary facilities to carry out this research. They are also thankful to DBT-IPLS project (Grant no: BT/PR4548/INF/22/146/2012), Punjabi University, Patiala, Punjab, India, for providing the HPTLC facility.

\section{AUTHORS' CONTRIBUTION}

Varinder Singh participated in the design of the study and drafted the manuscript. Naman Jain carried out the experiments, analyzed the data, and provided helpful feedback. Richa Shri provided the initial conception, designed the study, and reviewed and edited the manuscript.

\section{FUNDING}

There is no funding to report.

\section{CONFLICTS OF INTEREST}

The authors report no financial or any other conflicts of interest in this work.

\section{ETHICAL APPROVALS}

This study does not involve the use of animals or human subjects.

\section{PUBLISHER'S NOTE}

This journal remains neutral with regard to jurisdictional claims in published institutional affiliation.

\section{REFERENCES}

Aguiar S, Borowski T. Neuropharmacological review of the nootropic herb Bacopa monnieri. Rejuvenation Res, 2013; 16:313-26; doi:https://doi.org/10.1089/rej.2013.1431

Ahire ML, Walunj PR, Kishor PB, Nikam TD. Effect of sodium chloride-induced stress on growth, proline, glycine betaine accumulation, antioxidative defence and bacoside A content in in vitro regenerated shoots of Bacopa monnieri (L.) Pennell. Acta Physiol Plant, 2013; 35:1943-53; doi:10.1007/s11738-013-1233-x

Ahmed A, Ahmad S, Ur-Rahman M, Tajuddin TE, Verma R, Afzal M, Mehra PS. Quantitative analysis of bacoside A from Bacopa monnieri, collected from different geographic regions of India, by high-performance thin-layer chromatography-densitometry. J Planar Chromatogr, 2015; 28:287-93; doi:10.1556/1006.2015.28.4.4

Albergaria ET, Oliveira AFM, Albuquerque UP. The effect of water deficit stress on the composition of phenolic compounds in medicinal plants. S Afr J Bot, 2020; 131:12-7; doi:10.1016/j.sajb.2020.02.002
Amiri H, Dousty B, Hosseinzedeh SR. Water stress-induced changes of morphological, physiological and essential oil compounds in Thymus eriocalyx from Iran. J Essent Oil Bear Plants, 2018; 21:1210-23; doi:10.1080/0972060X.2018.1538817

Azhar N, Hussain B, Ashraf MY, Abbasi KY. Water stress mediated changes in growth, physiology and secondary metabolites of desi ajwain (Trachyspermum ammi L.). Pak J Bot, 2011; 43:15-9.

Bansal M, Kumar A, Reddy MS. Production of bacoside A, a memory enhancer from hairy root cultures of Bacopa monnieri (L.) Wettst. J Appl Res Med Aromat Plants, 2015; 2:92-101; doi:10.1016/j. jarmap.2015.05.001

Baruah A, Gogoi PK, Barua IC, Baruah D. Agronomic manipulation in brahmi (Bacopa monnieri) cultivation for higher productivity in Assam plains. J Krishi Vigyan, 2014; 2:11-3.

Bennett RN, Wallsgrove RM. Secondary metabolites in plant defence mechanisms. New Phytol, 1994; 127: 617-633.

Bhattacharya SK, Bhattacharya A, Kumar A, Ghosal S Antioxidant activity of Bacopa monniera in rat frontal cortex, striatum and hippocampus. Phytother Res, 2000; 14:174-79; doi:10.1002/(SICI)10991573(200005)14:3<174::AID-PTR624>3.0.CO;2-O

Blois MS. Antioxidant determinations by the use of a stable free radical. Nature, 1958; 181:1199-200; doi:10.1038/1811199a0

Board N. Herbs cultivation and their utilization. Asia Pacific Business Press Inc, Delhi, India, pp 358-62, 2003.

Chopra RN, Nayar SL, Chopra IC. Glossary of Indian medicinal plants. Council of Scientific \& Industrial Research, Delhi, India, p 32, 1956.

Ellman GL, Courtney KD, Andres V, Featherstone RM. A new and rapid colorimetric determination of acetylcholinesterase activity. Biochem Pharmacol, 1961; 7:88-95; doi:10.1016/0006-2952(61)90145-9

Farnsworth NR. Biological and phytochemical screening of plants. J Pharm Sci, 1966; 55:225-76; doi:10.1002/jps.2600550302

Farooqi AA, Sreeramu SS. Cultivation of medicinal and aromatic crops. Universities Press, Hyderabad, India, pp 66-70, 2004

Ghanbarzadeh Z, Mohsenzadeh S, Rowshan V, Moradshahi A. Evaluation of the growth, essential oil composition and antioxidant activity of Dracocephalum moldavica under water deficit stress and symbiosis with Claroideoglomus etunicatum and Micrococcus yunnanensis. Sci Hortic, 2019; 256:108652; doi:10.1016/j.scienta.2019.108652

Ghershenzon J. Changes in the levels of plant secondary metabolites under water and nutrient stress. In: Timmermann BN, Steelink C, Loewus FA, (eds.). Phytochemical adaptations to stress. Springer, New York, NY, pp 273-320, 1984; doi:10.1007/978-1-4684-1206-2_10

Hernández I, Alegre L, Munné-Bosch S. Enhanced oxidation of flavan-3-ols and proanthocyanidin accumulation in water-stressed tea plants Phytochemistry, 2006; 67:1120-6; doi:10.1016/j.phytochem.2006.04.002

Hodaei M, Rahimmalek M, Arzani A, Talebib M. The effect of water stress on phytochemical accumulation, bioactive compounds and expression of key genes involved in flavonoid biosynthesis in Chrysanthemum morifolium L. Ind Crops Prod, 2018; 120:295-304; doi:10.1016/j.indcrop.2018.04.073

Hussain AI, Anwar F, Sherazi ST, Przybylski R. Chemical composition, antioxidant and antimicrobial activities of basil (Ocimum basilicum) essential oils depends on seasonal variations. Food Chem, 2008; 108:986-95; doi:10.1016/j.foodchem.2007.12.010

JaleelCA, Sankar B, Murali PV, Gomathinayagam M, Lakshmanan GM, Panneerselvam R. Water deficit stress effects on reactive oxygen metabolism in Catharanthus roseus; impacts on ajmalicine accumulation. Colloids Surf B, 2008; 62:105-11; doi:10.1016/j.colsurfb.2007.09.026

Jauhari N, Bharadwaj R, Shama N, Bharadvaja N. Assessment of bacoside production, total phenol content and antioxidant potential of elicited and non-elicited shoot cultures of Bacopa monnieri (L.) J Environ Sustain, 2019; 2:441-53; doi:10.1007/s42398-019-00071-3

Khare CP. Indian medicinal plants: an illustrated dictionary. Springer Science \& Business Media, Berlin, Germany, p. 77, 2007.

Kleinwächter M, Selmar D. New insights explain that drought stress enhances the quality of spice and medicinal plants: potential 
applications. Agron Sustain Dev, 2015; 35:121-31; doi:10.1007/s13593014-0260-3

Masoumi H, Darvish F, Daneshian J, Normohammadi G, Habibi D. Effects of water deficit stress on seed yield and antioxidants content in soybean (Glycine max L.) cultivars. Afr J Agric Res, 2011; 6:1209-18.

Mathew M, Subramanian S. In vitro screening for anticholinesterase and antioxidant activity of methanolic extracts of ayurvedic medicinal plants used for cognitive disorders. PLoS One, 2014; 9:e86804; doi:10.1371/journal.pone.0086804

Mathur S, Gupta MM, Kumar S. Expression of growth and bacoside-A in response to seasonal variation in Bacopa monnieri accessions. J Med Aromat Plant Sci, 2000; 22:320-6.

Mathur S, Gupta MM, Ram M, Sharma S, Kumar S. Herb yield and bacoside-A content of field-grown Bacopa monnieri accessions. J Herbs Spices Med Plants, 2002; 9:11-8; doi:10.1300/J044v09n01 03

Pawar SS, Jadhav MG. Quantification of bacoside a from Bacopa monnieri (L.) by high performance thin layer chromatography. Int J Pharmacogn Phytochem Res, 2015; 7:1060-5.

Phrompittayarat W, Jetiyanon K, Wittaya-areekul S, Putalun W, Tanaka H, Khan I, Ingkaninan K. Influence of seasons, different plant parts, and plant growth stages on saponin quantity and distribution in Bacopa monnieri. Songklanakarin J Sci Techno, 2011; 33:193.

Pinto T, Lanctôt KL, Herrmann N. Revisiting the cholinergic hypothesis of behavioral and psychological symptoms in dementia of the Alzheimer's type. Ageing Res Rev, 2011; 10:404-12; doi:10.1016/j. arr.2011.01.003

Ramakrishna A, Ravishankar GA. Influence of abiotic stress signals on secondary metabolites in plants. Plant Signal Behav, 2011; 6:1720-31; doi:10.4161/psb.6.11.17613

Ramasamy S, Chin SP, Sukumaran SD, Buckle MJ, Kiew LV, Chung LY. In silico and in vitro analysis of bacoside A aglycones and its derivatives as the constituents responsible for the cognitive effects of Bacopa monnieri. PloS One, 2015; 10:e126565; doi:10.1371/journal. pone. 0126565

Randhawa K, Kumar D, Jamwal A, Kumar S. Screening of antidepressant activity and estimation of quercetin from Coccinia indica using TLC densitometry. Pharm Biol, 2015; 53:1867-74; doi:10.3109/138 80209.2015.1025289

Rejeb IB, Pastor V, Mauch-Mani B. Plant responses to simultaneous biotic and abiotic stress: molecular mechanisms. Plants, 2014; 3(4):458-75; doi:10.3390/plants3040458

Russo A, Borrelli, F. Bacopa monniera, a reputed nootropic plant an overview. Phytomedicine, 2005; 4:305-18; doi:10.1016/j. phymed.2003.12.008
Shanker AK, Venkateswarlu B. Abiotic stress in plants mechanisms and adaptations. InTech, Rijeka, Croatia, p 428, 2011; doi: $10.5772 / 895$

Sharma MU, Khajuria RK, Mallubhotla SH. Annual variation in bacoside content of Bacopa monnieri (L.) Wettst plants. Int J Pharm Bio Sci, 2013; 4:266-71.

Simpson T, Pase M, Stough C. Bacopa monnieri as an antioxidant therapy to reduce oxidative stress in the aging brain. J Evid Based Complementary Altern Med, 2015; 615384, 1-9. DOI: https://doi. org $/ 10.1155 / 2015 / 615384$

Singh HK. Brain enhancing ingredients from āyurvedic medicine: quintessential example of Bacopa monniera, a narrative review. Nutrients, 2013; 5:478-97; doi: 10.3390/nu5020478

Singh HK, Rastogi RP, Srimal RC, Dhawan BN. Effect of bacosides A and B on avoidance responses in rats. Phytother Res, 1988; 2:70-5; doi:10.1002/ptr.2650020205

Singh M, Kaur M, Kukreja H, Chugh R, Silakari O, Singh D. Acetylcholinesterase inhibitors as Alzheimer therapy: from nerve toxins to neuroprotection. Eur J Med Chem, 2013; 70:165-88; doi:10.1016/j. ejmech.2013.09.050

Singh V, Krishan P, Singh N, Kumar A, Shri R. Amelioration of ischemia-reperfusion induced functional and biochemical deficit in mice by Ocimum kilimandscharicum leaf extract. Biomed Pharmacother, 2017; 85:556-63; doi:10.1016/j.biopha.2016.11.064

Sukumaran NP, Amalraj A, Gopi S. Neuropharmacological and cognitive effects of Bacopa monnieri (L.) Wettst - A review on its mechanistic aspects. Complement Ther Med, 2019; 44:68-82; doi:10.1016/j. ctim.2019.03.016

Zhu Z, Liang Z, Han R. Saikosaponin accumulation and antioxidative protection in drought-stressed Bupleurum chinense DC. plants Environ Exp Bot, 2009; 66:326-33; doi:10.1016/j.envexpbot.2009.03.017

Zobayed SM, Afreen F, Kozai T. Phytochemical and physiological changes in the leaves of St. John's wort plants under a water stress condition. Environ Exp Bot, 2007; 59:109-16; doi:10.1016/j.envexpbot.2005.10.002

\section{How to cite this article:}

Singh V, Jain N, Shri R. Effect of abiotic factors on bacoside A content, acetylcholinesterase inhibitory and antioxidant activities of Bacopa monnieri (L.) Wettst. J Appl Pharm Sci, 2021; 11 (Supp 1):063-070. 